\title{
High-resolution simulation of link-level vehicle emissions and concentra- tions for air pollutants in a traffic-populated eastern Asian city
}

Shaojun Zhang et al.

Correspondence to: Ye Wu (ywu@tsinghua.edu.cn)

The copyright of individual parts of the supplement might differ from the CC-BY 3.0 licence. 


\section{Supplementary Tables}

2

3 Table S1. Estimated traffic activity by vehicle category in Macau during a typical weekday of 2010

\begin{tabular}{cccc}
\hline Vehicle category & $\begin{array}{c}\text { Traffic activity } \\
(\text { veh km d }\end{array}$ & Vehicle category & $\begin{array}{c}\text { Traffic activity } \\
\left(\text { veh km d }^{-1}\right)\end{array}$ \\
\hline LDPV & $1.72 \times 10^{6}$ & Taxi & $6.01 \times 10^{5}$ \\
MDPV & $1.08 \times 10^{5}$ & Motorcycle & $1.23 \times 10^{6}$ \\
HDPV & $8.44 \times 10^{4}$ & LDT & $1.37 \times 10^{5}$ \\
Public bus & $1.42 \times 10^{5}$ & HDT & $2.12 \times 10^{4}$ \\
\hline
\end{tabular}


1 Table S2. Spatial allocation of vehicle emissions in Macau during a typical weekday of 2010

\begin{tabular}{|c|c|c|c|c|c|}
\hline \multirow{2}{*}{ Region / Parish } & \multicolumn{5}{|c|}{ Allocation of vehicle emissions } \\
\hline & $\mathrm{CO}$ & THC & $\mathrm{NO}_{\mathrm{X}}$ & $\mathrm{PM}_{2.5}$ & $\mathrm{CO}_{2}$ \\
\hline Macau Peninsula & $76 \%$ & $78 \%$ & $58 \%$ & $52 \%$ & $59 \%$ \\
\hline St. Lazarus Parish & $12 \%$ & $12 \%$ & $9 \%$ & $8 \%$ & $9 \%$ \\
\hline St. Lawrence Parish & $8 \%$ & $8 \%$ & $6 \%$ & $5 \%$ & $6 \%$ \\
\hline Our Lady Fatima Parish & $23 \%$ & $25 \%$ & $17 \%$ & $15 \%$ & $18 \%$ \\
\hline St. Anthony Parish & $16 \%$ & $17 \%$ & $12 \%$ & $10 \%$ & $13 \%$ \\
\hline Cathedral Parish & $16 \%$ & $16 \%$ & $14 \%$ & $13 \%$ & $13 \%$ \\
\hline Taipa & $12 \%$ & $10 \%$ & $21 \%$ & $23 \%$ & $19 \%$ \\
\hline CoTai Reclamation Area & $5 \%$ & $5 \%$ & $9 \%$ & $10 \%$ & $8 \%$ \\
\hline Coloane & $2 \%$ & $2 \%$ & $2 \%$ & $2 \%$ & $3 \%$ \\
\hline Others (three cross-sea bridges) & $6 \%$ & $5 \%$ & $10 \%$ & $13 \%$ & $10 \%$ \\
\hline
\end{tabular}




\section{Supplementary Figures}

2

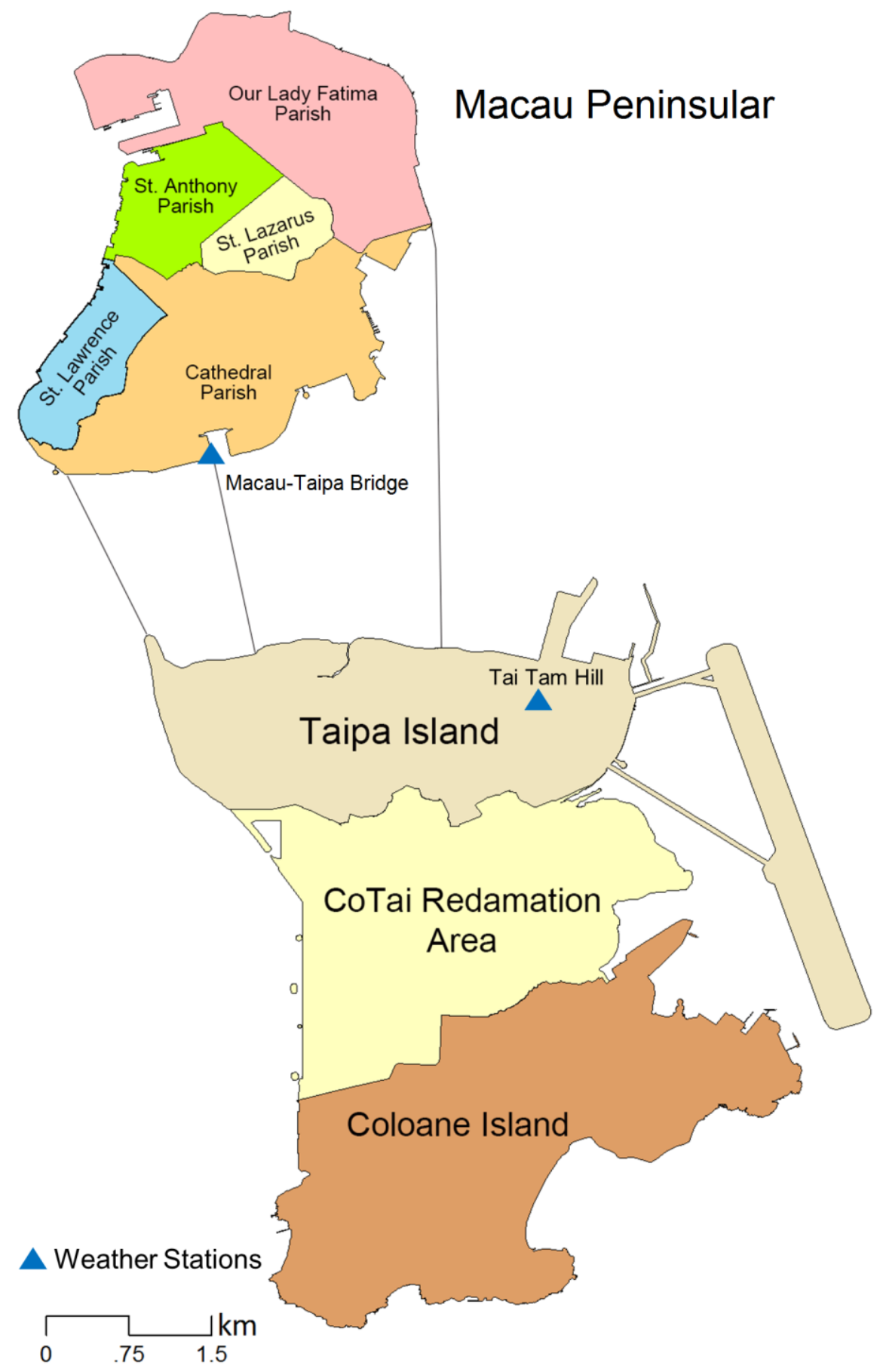

4 Fig. S1. Map of the Special Administrative Region of Macau, China

5 Two weather stations are marked in the figure. 


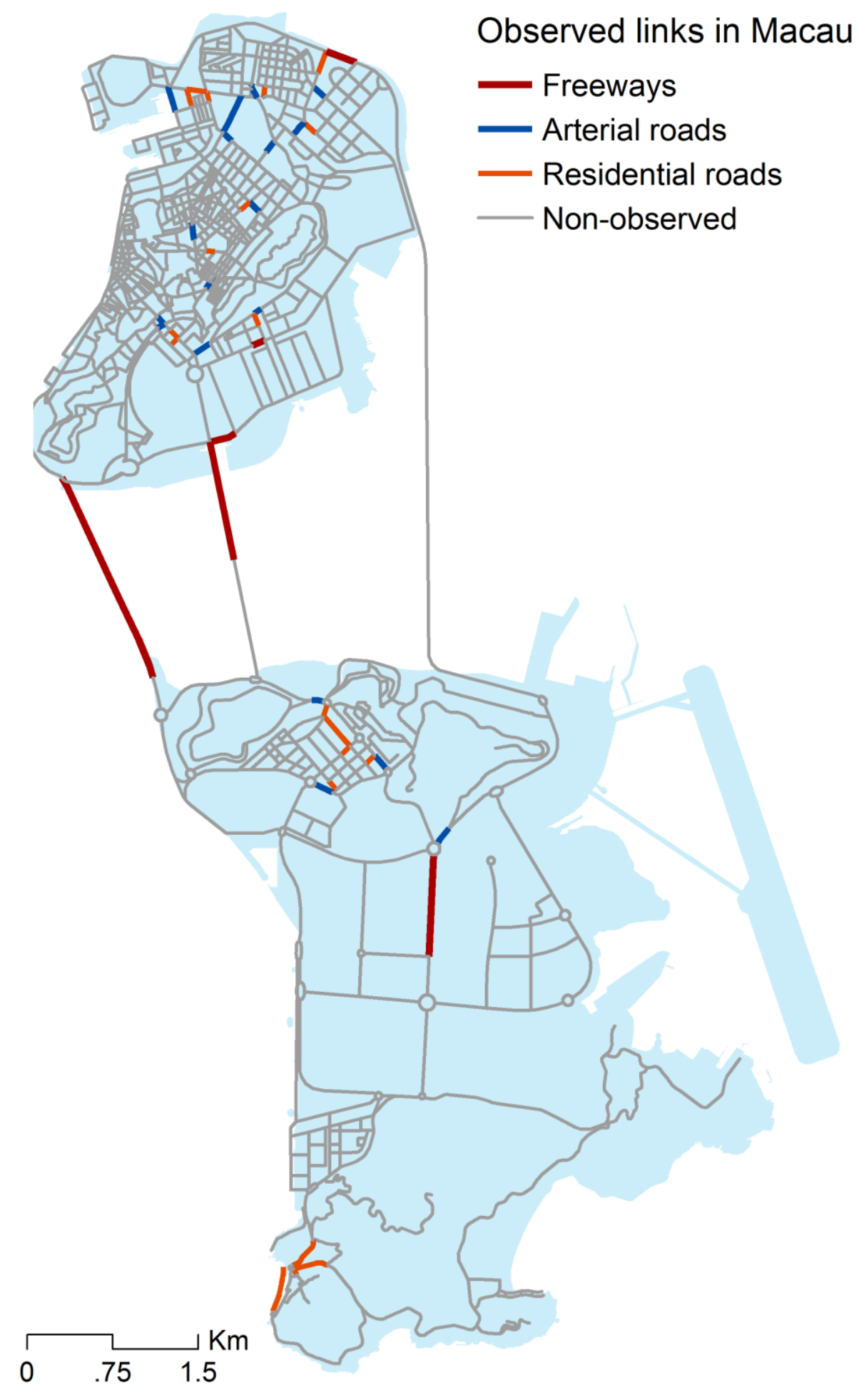

Fig. S2. Map of the road links with observed traffic volume data 3 

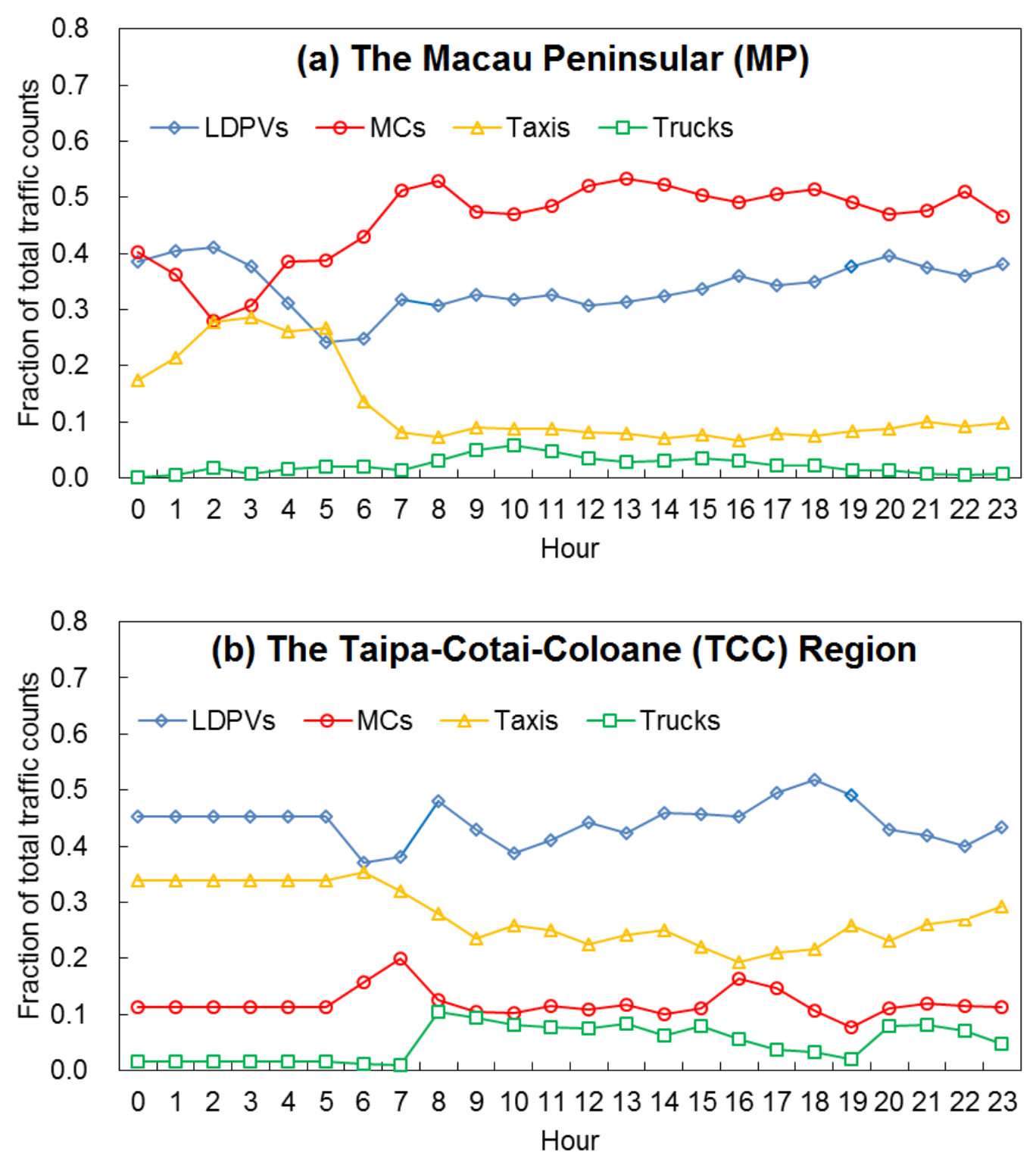

Fig. S3. Hourly allocations of traffic volume for LDPVs, motorcycles, taxis and trucks on the arterial roads in (a) the Macau Peninsula and (b) the Taipa-Cotai-Coloane Region.

6 Note: Hourly truck volume data in this figure is the combined results for LDTs and HDTs. 


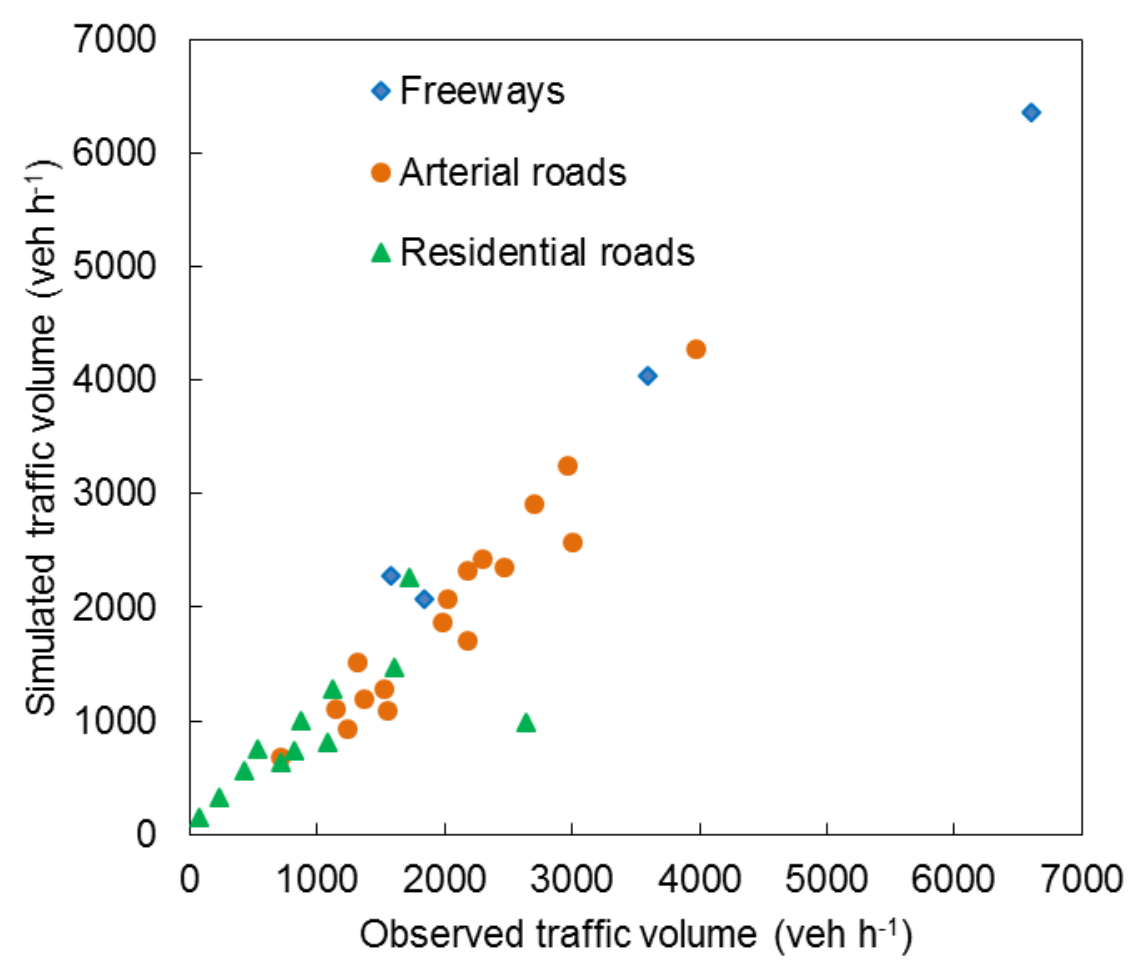

2 Fig. S4. Comparison of observed traffic volume and simulated results with the TransCAD model for 33 3 roads during 6 p.m. hour of typical weekdays 


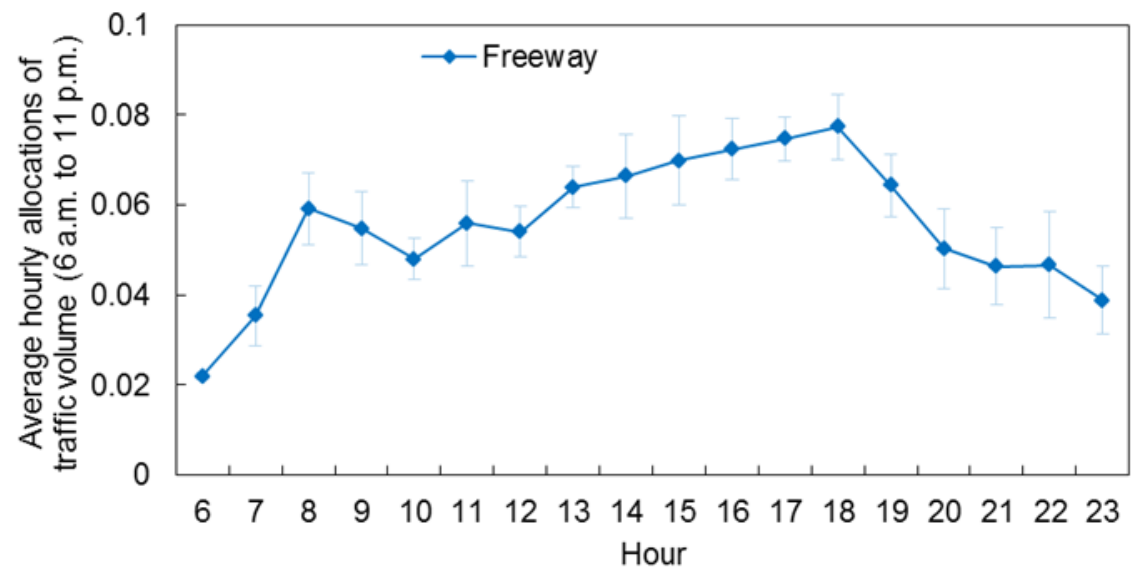

1

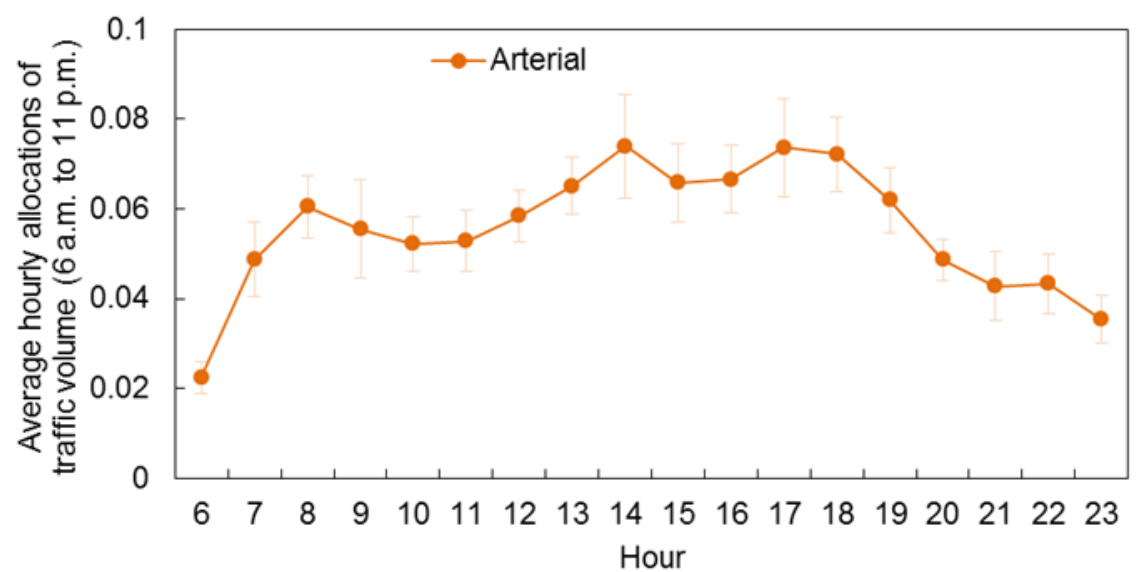

2

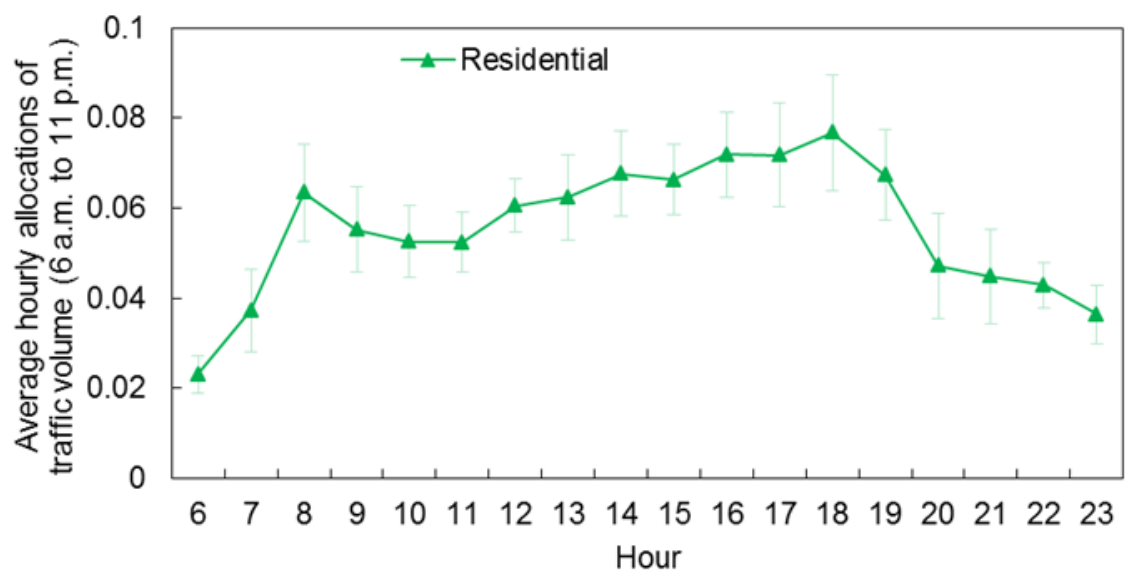

3

4 Fig. S5. Average allocations of hourly traffic volume in the total traffic volume from 6 a.m. to 11 p.m. 5 Only roads with observed traffic volume data are included. 


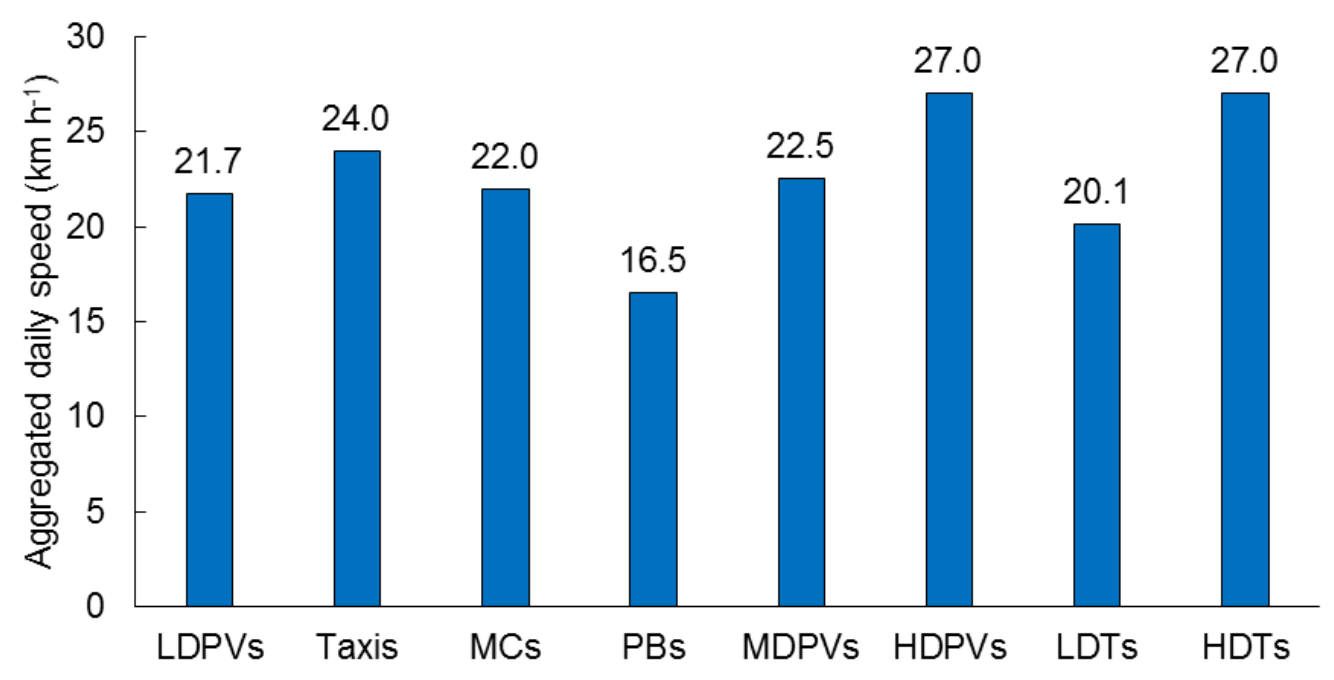

2 Fig. S6. Fleet-average speed of each vehicle category in Macau, during a typical weekday of 2010. 3 


\section{(a) Macau-Taipa Bridge}

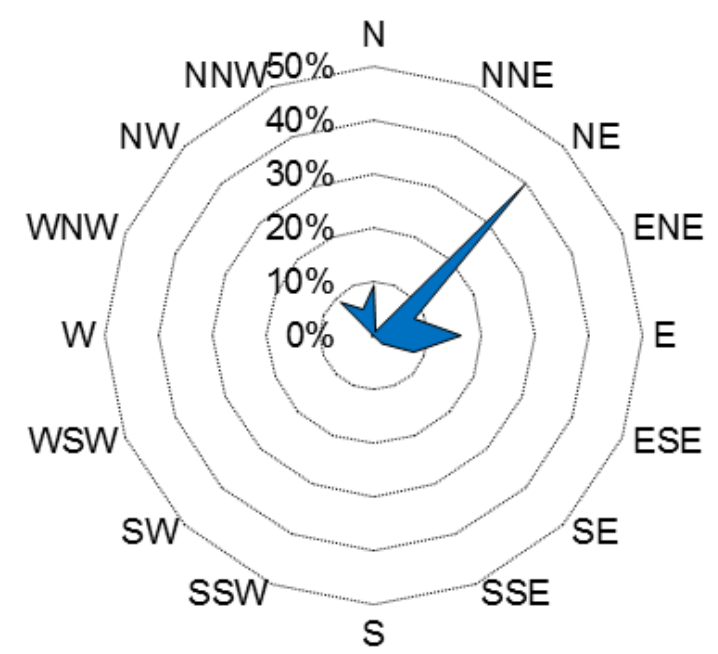

(b) Tai Tam Hill

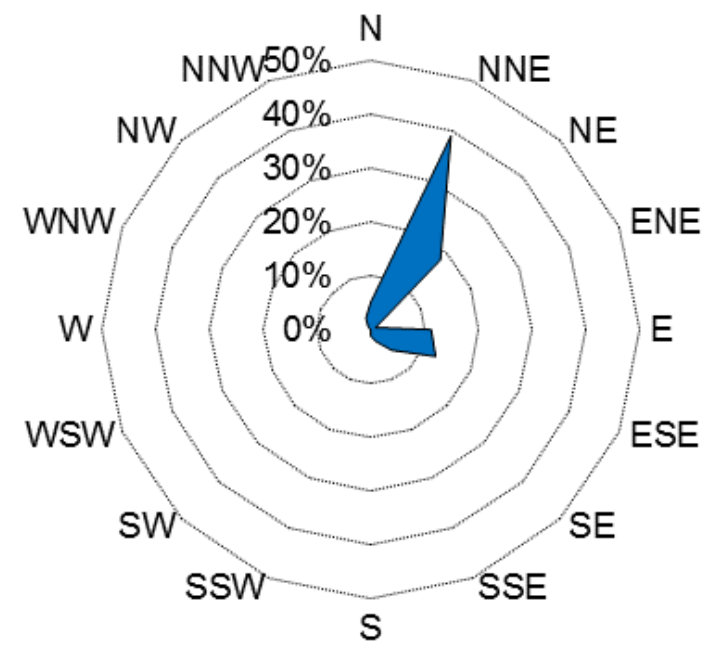

2

Fig. S7. Wind rose map of two weather stations in Macau during weekdays of November 2010. 


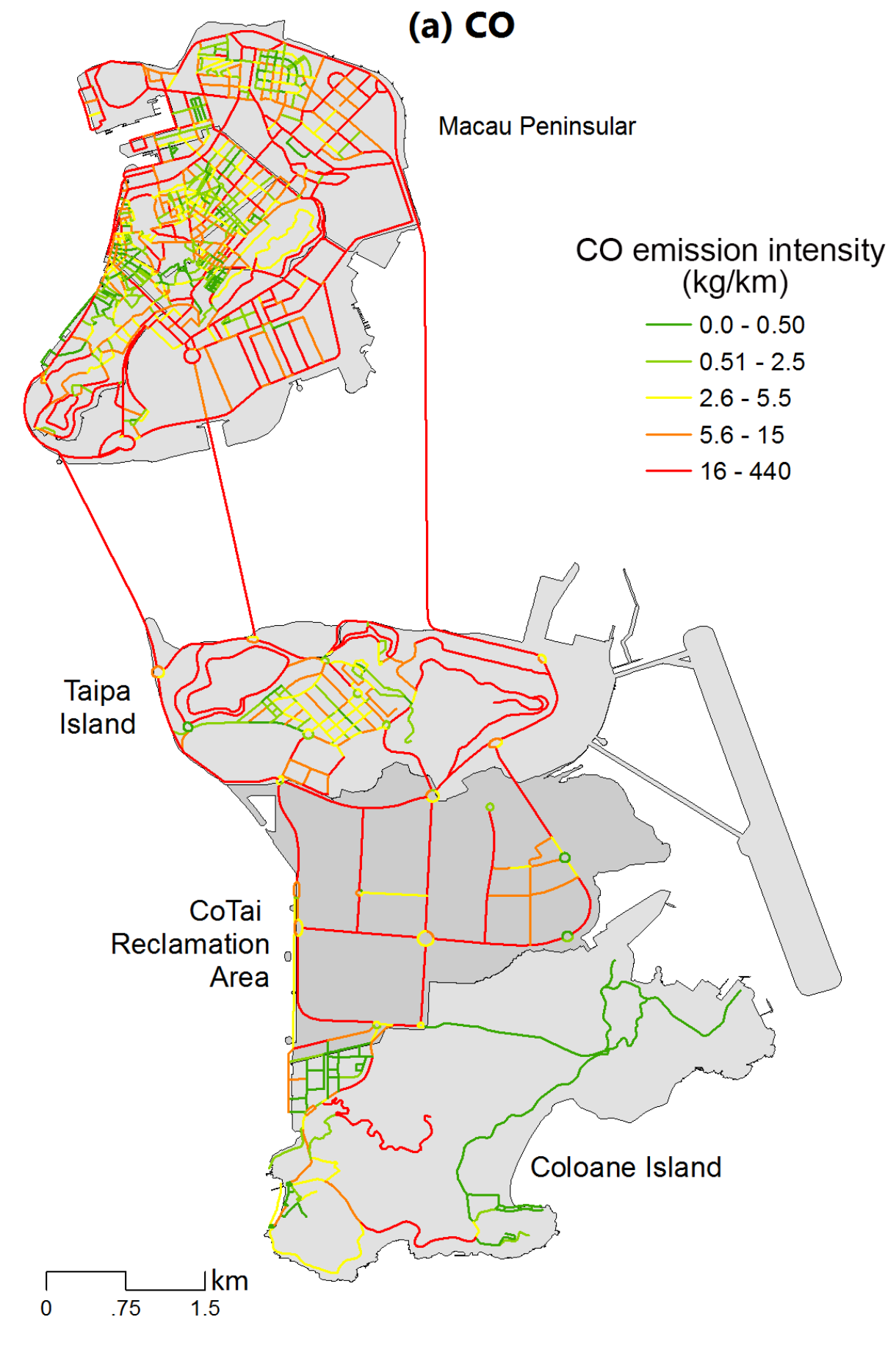




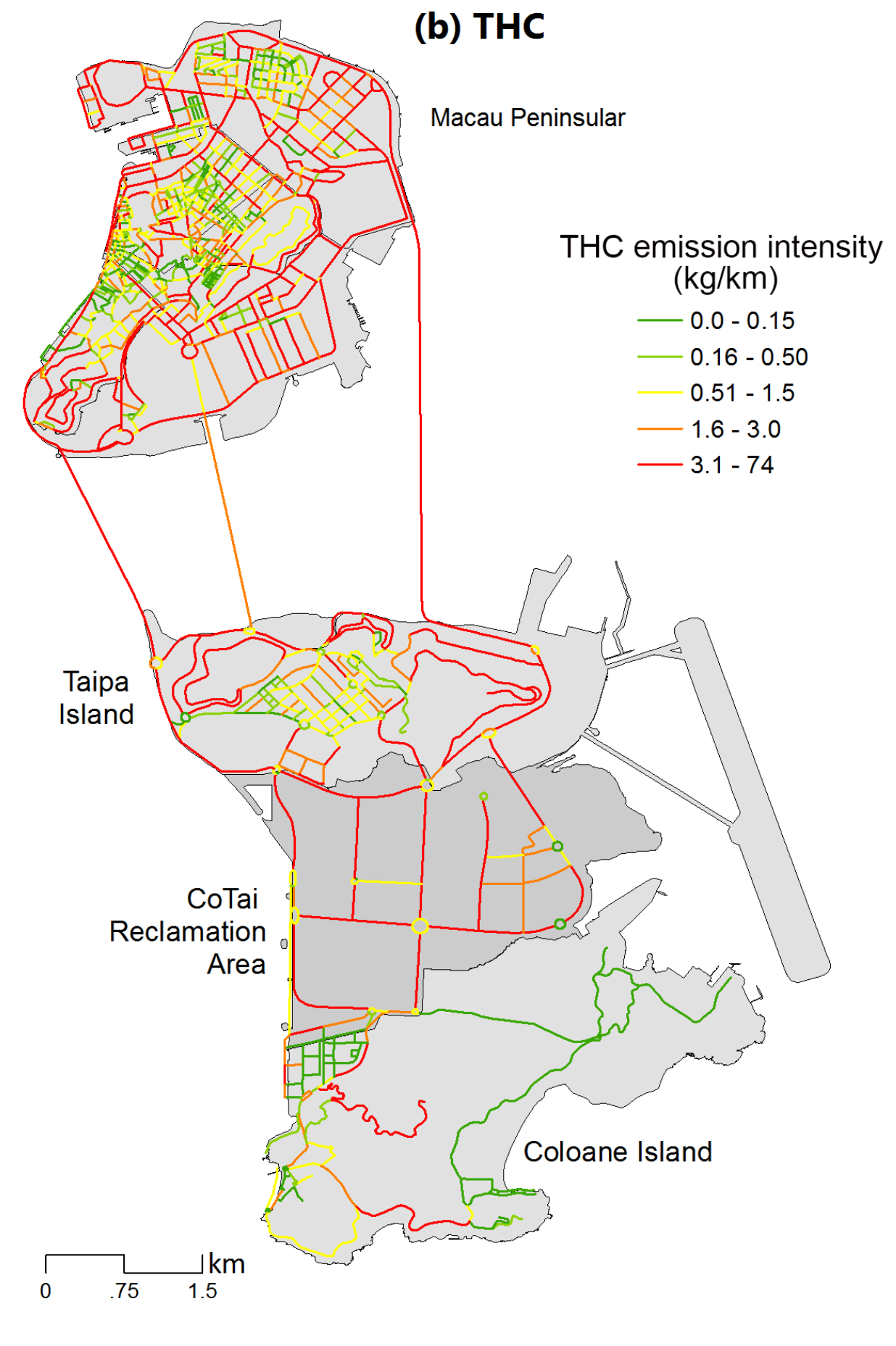




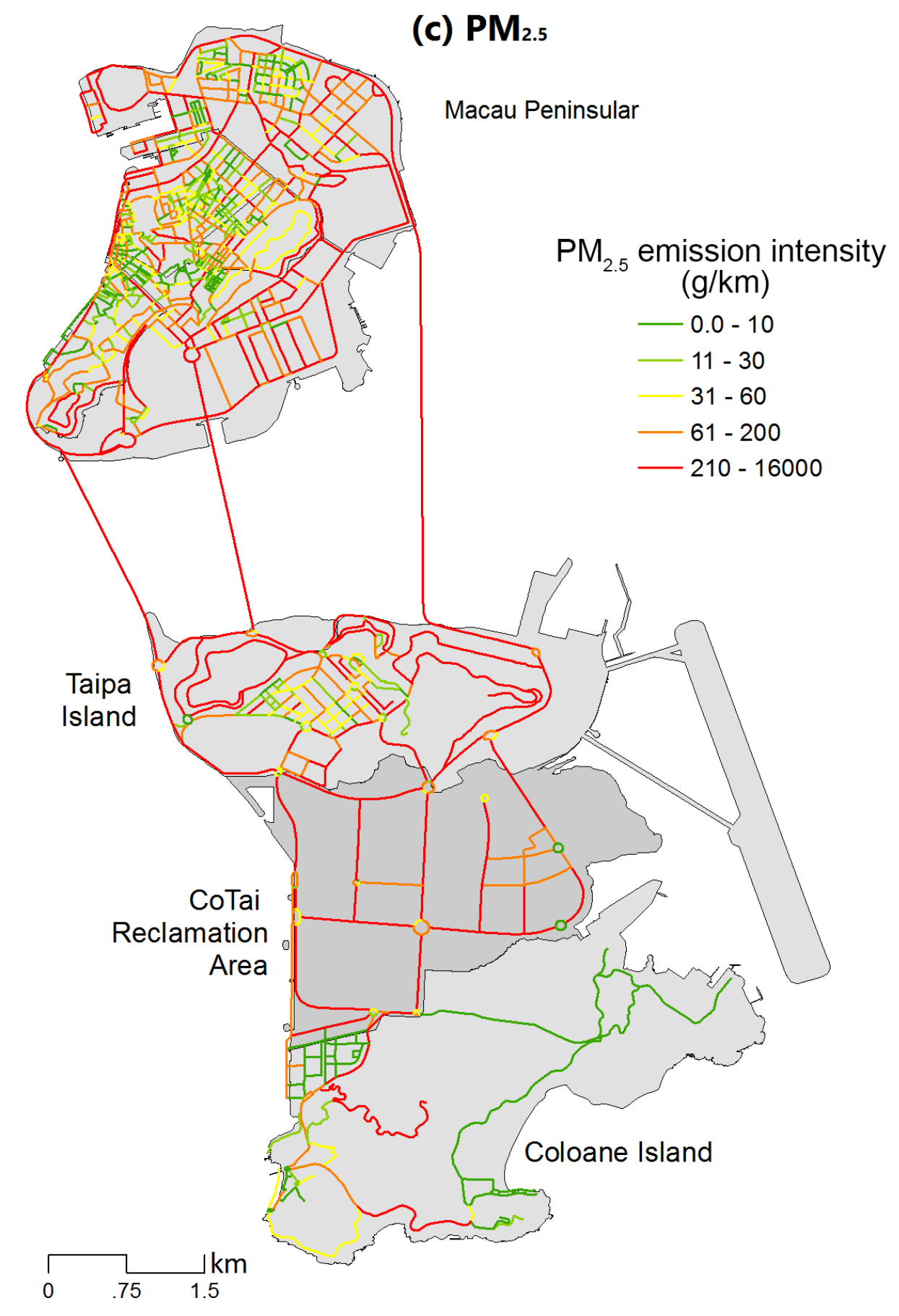

2 Fig. S8. The spatial distribution of vehicle emissions for (a) CO, (b) THC, (c) $\mathrm{PM}_{2.5}$ and (d) $\mathrm{CO}_{2}$ in 3 Macau during a typical weekday of 2010 


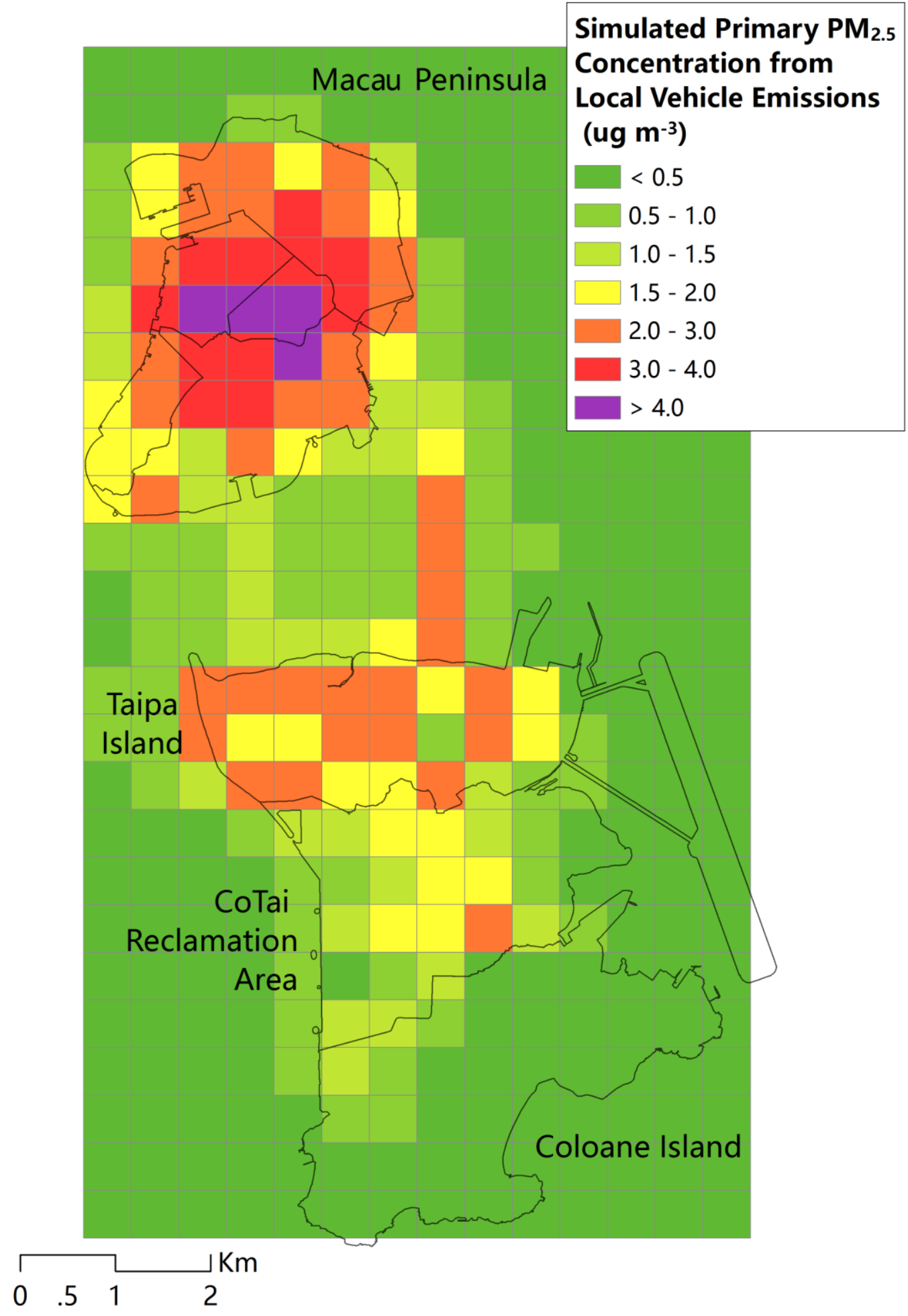

2 Fig. S9. Simulated vehicle-contributed concentrations of $\mathrm{PM}_{2.5}$ in Macau during weekdays of 3 November, 2010 


\section{Air Quality Modeling with the CMAQ model}

3 In this study, the Weather Research Forecasting model (WRF, version 3.3) and Community Multiscale 4 Air Quality model (CMAQ, version 4.7.1) were employed to investigate impacts from regional background, cross-boundary transport and other area sources. National Centers for Environmental Prediction (NCEP) and the automated data processing (ADP) data, with a resolution of $1^{\circ} \times 1^{\circ}$ were used as initial guess fields of WRF. Four-dimensional data assimilation (FDDA) is applied for objective analysis. Detailed physical parameterizations include the Kain-Fritsch 2 cumulus scheme, the Pleim-Xiu PBL scheme and land surface model, the mixed phase explicit moisture scheme for cloud microphysics,

11 longwave radiation scheme. The Meteorology Chemistry Interface Processor (MCIP) version 3.6 was 12 applied to process the meteorological data to the data format for CMAQ. CB-05 gas-phase chemical 13 mechanism with AERO5 aerosol module were used. The aerosol thermodynamic equilibrium model is 14 ISORROPIA.

15

16 17 18

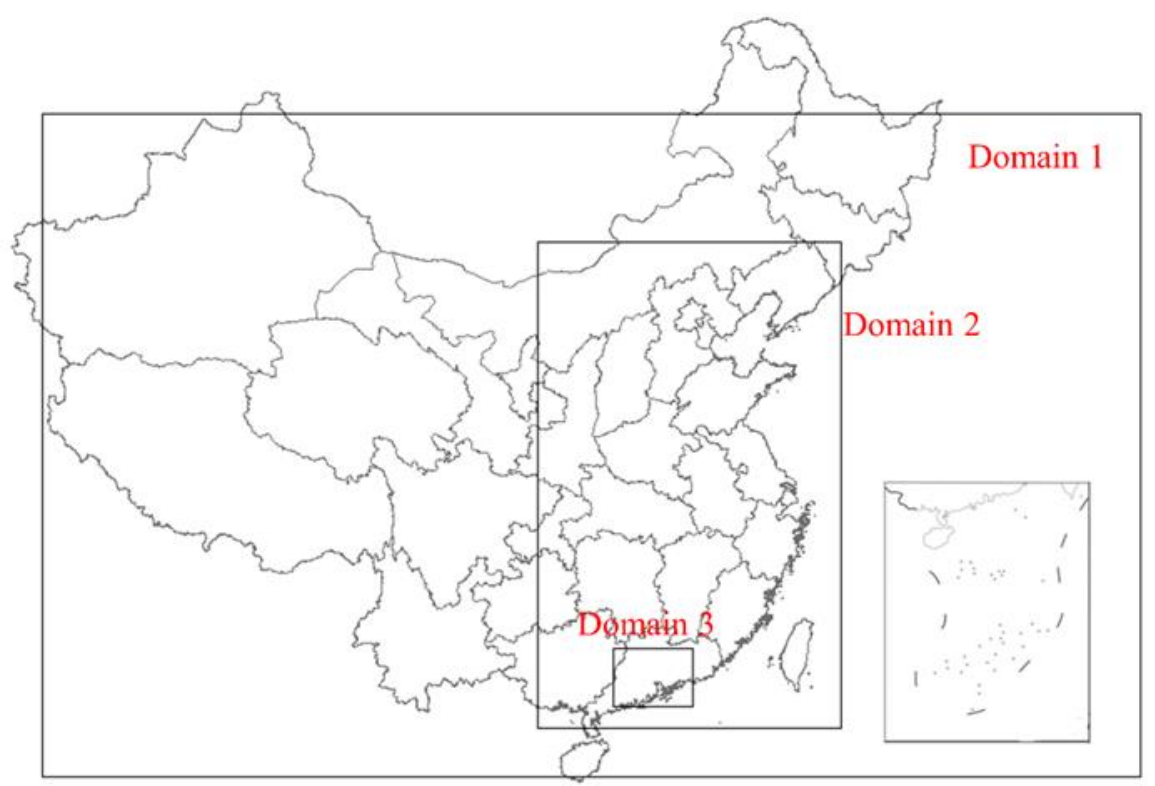

Fig. S10. Triple-nested simulation domain of CMAQ at a horizontal grid resolution of $36 \mathrm{~km}, 12 \mathrm{~km}$ and $4 \mathrm{~km}$.

A triple-nested simulation domain, shown in Figure S10, was used in this study. Domain 1 covers most of China of $36 \mathrm{~km} \times 36 \mathrm{~km}$ horizontal resolution. Domain 2 covers East of China with $12 \mathrm{~km} \times 12 \mathrm{~km}$ horizontal resolution. Domain 3 covers Perl River Delta (PRD) with $4 \mathrm{~km} \times 4 \mathrm{~km}$ horizontal resolution. 23 vertical layers $(\sigma: 1.000 、 0.995 、 0.988 、 0.980 、 0.970 、 0.956 、 0.938 、 0.916 、 0.893 、 0.868 、 0.839$ 、 
$10.808 、 0.777 、 0.744 、 0.702 、 0.648 、 0.582 、 0.500 、 0.400 、 0.300 、 0.200 、 0.120 、 0.052$ and 0.000 )

2 were included ranging from surface to 100 mbar. The configurations of chemical initial conditions and

3 boundary conditions, and regional emission inventory are consistent with our previous papers (Zhao et al 4 2013a, 2013b). The local emissions for other sectors (e.g., residential, power, and industrial sectors) in

5 Macau were provided by the Macau Environmental Protection Bureau, together with the vehicle emissions

6 estimated by this study. The simulated results of regional air quality are presented in Fig. S11.

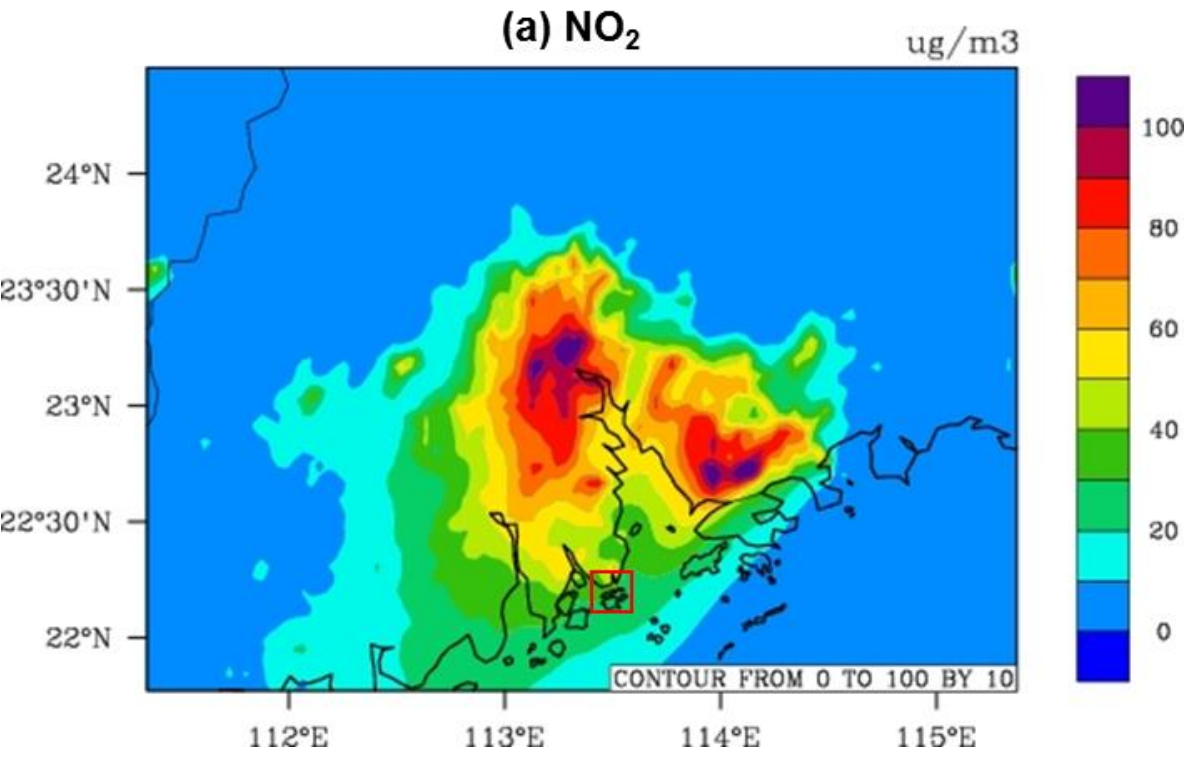

(b) $\mathrm{PM}_{2.5}$

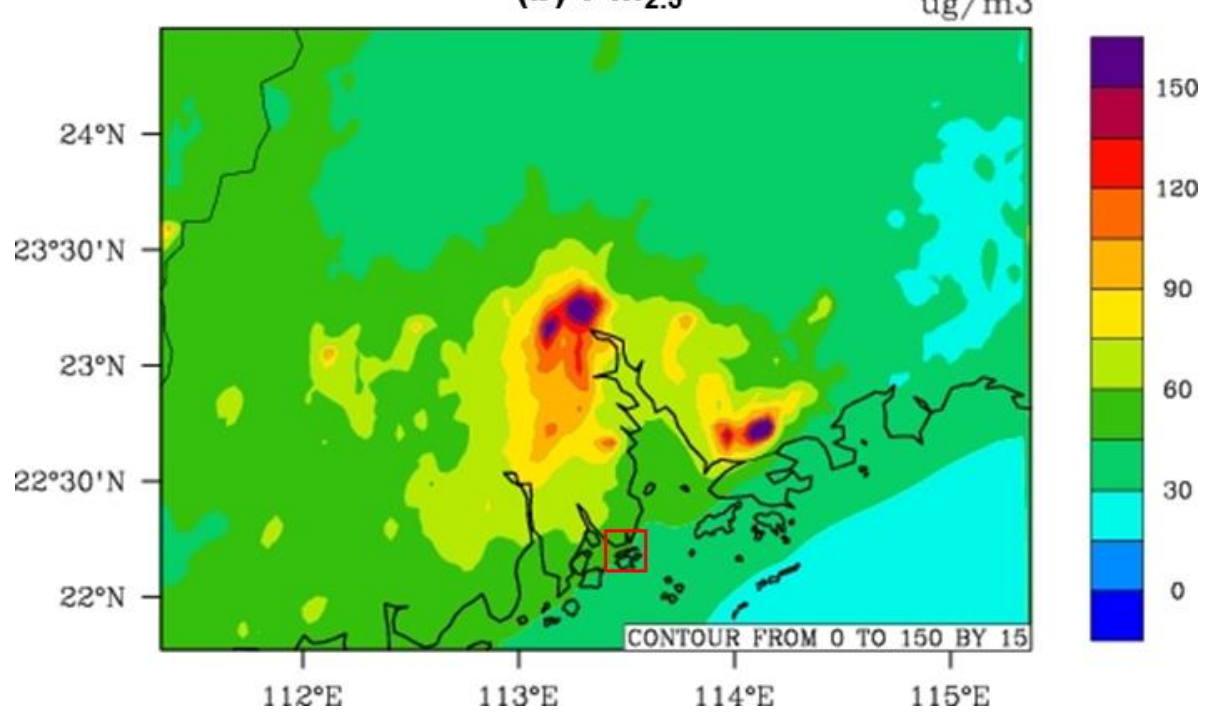

Fig. S11. Monthly average of simulated concentrations for $\mathrm{NO}_{2}$ and $\mathrm{PM}_{2.5}$ in the Pearl River Delta

11 Region (i.e., Domain 3), November 2010 
2 Simulated monthly average concentrations of $\mathrm{NO}_{2}$ and $\mathrm{PM}_{2.5}$ (November 2010) of the $4 \mathrm{~km} \times 4 \mathrm{~km}$ cells

3 are presented in Table S3, within which the air quality stations are located. We also include the observed

$4 \quad \mathrm{NO}_{2}$ and $\mathrm{PM}_{10}$ concentrations during November 2010 for comparison. It is noted that the $\mathrm{PM}_{2.5}$ monitoring

5 was not conducted in Macau until July 2012. The one-year monitoring results in 2013 indicate that the

6 mass fraction of $\mathrm{PM}_{2.5}$ in $\mathrm{PM}_{10}$ was approximately 60\%. The CMAQ model is not capable of the high $\mathrm{NO}_{2}$

7 concentrations in Macau with normalized mean bias of $-37 \%$ to $55 \%$. On the other hand, although the

8 AERMOD model may yield higher $\mathrm{NO}_{2}$ concentrations in traffic populated areas, however, the model

9 limitations would bring in considerable uncertainty (e.g., diurnal fluctuations). Thus, we suggest that

10 future efforts are required to develop more advanced air quality model to enhance spatial heterogeneity

11 and chemical transport at the same time.

12

13 Table S3. Comparison of simulated and observed air pollutant concentrations, monthly average of 14 November 2010 ( $\mu \mathrm{g} \mathrm{m}^{-3}$, mean \pm standard deviation)

\begin{tabular}{cccc|ccc}
\hline $\begin{array}{c}\text { Monitoring } \\
\text { sites }\end{array}$ & $\begin{array}{c}\text { Observed } \\
\mathrm{NO}_{2}\end{array}$ & $\begin{array}{c}\text { Simulated } \\
\mathrm{NO}_{2}\end{array}$ & $\mathrm{NMB}$ & $\begin{array}{c}\text { Observed } \\
\mathrm{PM}_{10}\end{array}$ & $\begin{array}{c}\text { Simulated } \\
\mathrm{PM}_{2.5}\end{array}$ & $\begin{array}{c}\text { NMB } \\
\mathrm{a}\end{array}$ \\
\hline MP 1 & $68.0 \pm 12.7$ & $37.8 \pm 16.7$ & $-44 \%$ & $99.1 \pm 28.6$ & $41.2 \pm 18.3$ & $-31 \%$ \\
MP 2 & $64.9 \pm 13.1$ & $40.8 \pm 14.3$ & $-37 \%$ & $96.6 \pm 30.3$ & $41.8 \pm 17.1$ & $-28 \%$ \\
Taipa 1 & $52.2 \pm 10.4$ & $33.1 \pm 16.8$ & $-37 \%$ & $84.8 \pm 23.1$ & $37.0 \pm 16.7$ & $-27 \%$ \\
Taipa 2 & $55.1 \pm 14.8$ & $29.3 \pm 15.9$ & $-47 \%$ & $86.5 \pm 14.8$ & $33.2 \pm 16.6$ & $-36 \%$ \\
Coloane & $65.0 \pm 17.3$ & $29.8 \pm 16.5$ & $-54 \%$ & $86.1 \pm 24.9$ & $34.8 \pm 17.8$ & $-33 \%$ \\
\hline
\end{tabular}

Note: ${ }^{\mathrm{a}} \mathrm{We}$ assume that the mass fraction of $\mathrm{PM}_{2.5}$ in $\mathrm{PM}_{10}$ was 0.6.

References

Zhao, B.; Wang, S. X.; Dong, X. Y.; Wang, J. D.; Duan, L.; Fu, X.; Hao, J. M.; Fu, J., Environmental effects of the recent emission changes in China: implications for particulate matter pollution and soil acidification. Environmental Research Letters 2013a, 8, (2).

Zhao, B.; Wang, S.; Wang, J.; Fu, J. S.; Liu, T.; Xu, J.; Fu, X.; Hao, J., Impact of national NOx and $\mathrm{SO}_{2}$ control policies on particulate matter pollution in China. Atmospheric Environment 2013b, 77, (0), 453463. 